\title{
Effectiveness of Moringa Oleifera Extract to Increase Breastmilk Production in Postpartum Mother with Food Restriction
}

\author{
Rini Kristiyanti ${ }^{1}$, Siti Khuzaiyah ${ }^{1 *}$, Nur Chabibah ${ }^{1}$, M Khanifah $^{1}$ \\ ${ }^{1}$ Midwifery Department, University of Muhammadiyah Pekajangan Pekalongan, Pekalongan, Indonesia \\ *Corresponding author. Email: khuzaiyahpenulis@gmail.com
}

\begin{abstract}
Breast Milk is the most complete, safe, hygienic and inexpensive nutritious food. However, the culture of food restriction in the community is often a barrier to improving nutrition for both the mother and her baby. The purpose of this study was to determine the effectiveness of giving Moringa leaf extract in increasing the productivity of breast milk in postpartum mothers who abstain from several kinds of food. This study was a quasi-experimental study with pre-test and post-test control group design approach. The samples were postpartum mothers avoiding food in the work area of Pekalongan District health center, the sampling technique was purposive sampling in the field of the community health center in Pekalongan regency. Breast milk production is measured based on the baby's weight gain. The data was analyzed by using paired t-test and Mann Whitney test. There were significant differences in breastmilk production before and after giving Moringa Oliefera extract with p-value 0,000 and CI (-1308.934) - (-814.595). Analysis in the control group contained a significant difference in mean before and after giving Moringa extract with p-value 0.000 and CI (-1098.988) - (-751.012). There was a mean difference between those given Moringa extract and which were only monitored without giving Moringa extract with a p-value of 0.049 . This study shows that the Moringa extract effectively increases milk production with indicators that there was a difference in weight gain in infants between the control group and the experimental group. It was expected that the results of this study could be one of the references in the implementation of midwifery care for postpartum mothers. Research with wider variables and more respondents is needed.
\end{abstract}

Keywords: Moringa Oleifera extract, breastmilk, food

\section{INTRODUCTION}

Breast milk is the best form of nutrition for a child that provides the nutrients a growing infant needs in the most digestible form [1], and the legal protection for exclusive breastfeeding for infants has obtained public law protection [2]. Food consumed by mothers strongly influence breastmilk production. If mothers eat regularly and contain enough of the nutrients they need, it will affect milk production, because the breastmilk gland cannot work perfectly without adequate food. The mother's food must meet the number of calories, protein, fat, and vitamins and minerals that are sufficient. On average, for the first six months of breastfeeding, women need 330 more calories a day than they did before they were pregnant. In the six months of breastfeeding, they need 400 calories a day more than their pre-pregnancy needs [1]. Breastmilk with good nutrition can breastfeed a baby for at least six months. In mothers with poor nutrition, they are not able to breastfeed their babies within that period, even some of the milk is not out. Unfortunately, some mothers did self-food restriction to the several kinds of foods. Food ingredients that are not consumed in certain conditions due to cultural factors are called food abstinence. In Korean, the most common selfrestricted foods were caffeine $(\mathrm{n}=131,90.3 \%)$, spicy foods $(\mathrm{n}=124,85.5 \%)$, raw foods $(\mathrm{n}=109,75.2 \%)$, cold foods $(\mathrm{n}=100,69 \%)$, and sikhye (traditional sweet Korean rice beverage $)(n=100,69 \%)$. Most mothers $(n=122,84.1 \%)$ avoided foods for vague reasons [3]. In Indonesian, postpartum mothers abstain for several kinds of foods such as egg, fish, meat, and seasoned food.

Myths often make breastfeeding mothers have difficulty choosing food, so mothers have taboos to consume various types of food, so breast milk production is disrupted. On the other hand, health care should ensure that mothers get enough nutrition so that breast-milk can be optimally produced. If the mothers did not get enough micronutrient, it would affect the ability to provide breast milk containing sufficient micronutrients for growing baby [4].

The tactical approach is an effort to improve the nutritional status of infants as a reflection of the nutrition of breastfeeding mothers and their reduction efforts through various studies or studies related to abstinence from postpartum mothers, but cultural aspects tend to be difficult to remove from the community, so there are still postpartum mothers who abstain from food during the first forty days of breastfeeding. Alternative post-partum supplementation by giving moringa leaf extract to postpartum mothers who refuse from several kinds of foods. 
Moringa oleifera leaves are essential sources of $\beta$-carotene and other vitamins, minerals and amino acids. It contains all the essential amino acids as well as polyunsaturated fatty acids including $\alpha$-linolenic acid. Besides, M. oleifera leaves are rich sources of phytochemicals that potent anticancer and hypotensive activity and are considered full of medicinal properties [5]. Leaf powder of moringa increased the productivity of breast milk in mice [6]. Studies of the effects of $M$. oleifera to the breastmilk production were done. Unfortunately, the impacts of the M. oleifera on the mother with food restriction have not been reported yet. The purpose of this study was to determine the effectiveness of giving Moringa leaf extract in increasing the productivity of breast milk in postpartum mothers who abstain from several kinds of food.

\section{METHOD}

\subsection{Research Design and Intervention}

This study was a quasi-experimental with pre-test and posttest control group design approach. In this study, there were two groups: the intervention group with giving Moringa oliefera and the standard postpartum care group (as a control group). The researcher used a random technique to determine the group members. In the first meeting, in the 7 th day of postpartum, both the intervention and control group had been assessed regarding the breastmilk frequency and baby weight. Then, the intervention group got standard postnatal care, health education education-about breastfeeding and abstained from food, and Respondents were given Moringa extract as much as 120 tablets to be taken twice a day x@ two capsules for 30 days. Meanwhile, In the control group the researcher only came to the respondent on the 7 th day and a month afterwards to provide health education and conduct a baby examination (including weighing) without giving supplements to Moringa-extract.

\subsection{Participants}

The population in this study were the postpartum mother who did food restriction in the working area of the Kedungwuni I and II of Community Health Centre in 2016. Purposive sampling had been used in taking respondents. The total numbers of the respondent were 34 . The inclusion criteria were post-partum in the 7th-10th day, did food restriction, spontaneous post-partum, and did exclusive breastfeeding. The exclusion criteria were: mothers who did has no intention to be respondents, postnatal mothers who consumed breast milk booster, post-partum mothers with any health complication and post-partum mothers who did not consume Moringa oleifera regularly.

\subsection{Instrument}

The main tools and materials in this study were baby's weight-scale, moringa oleifera tablet, and supporting data collection tools that were questionnaire which could record: age, gravida, labour history, knowledge, breastfeeding frequency, breastfeeding problem and the result of the baby weight.

\subsection{Data Collection}

The researcher did data collection after obtaining a research permit from all relevant parties. Then, researchers contacted and met the respondents, explained the aim of the research, and offer a willingness to become a respondent. Afterwards, researchers determined respondents based on inclusion and exclusion criteria. The selected respondents were asked to fill out an informed consent sheet. The researcher gave moringa oleifera leaf extract to the respondents and explained how to consume those. The baseline data was collected in the first meeting before treatment including breastfeeding frequency and baby's weight. The postintervention data was taken at the final session after finishing treatment.

\subsection{Data Analysis}

Descriptive analysis was used to analyse the characteristics of the subjects. Data analyse for each variable used a frequency distribution. Categorical data are presented in the form of frequencies and percentages. The independent variable in this study was Moringa leaf extract. The dependent variable in this study was the increase of breast milk production (measured by the baby weight delta). The first bivariable analysis in this study was to compare the pretest mean and post-test mean interventions. Before the data was analysed, a data normality test was performed. Data were analysed using a paired t-test on the differences in the mean of the control and treatment groups. The significance level used in this test was $p$-value $<0.05$ at $95 \%$ confidence interventions.

The test used in testing dependent variables with external variables was based on the type of data obtained. Variables that are not normally distributed was tested with nonparametric tests, while variables that are normally distributed was tested using the independent t-test.

\subsection{Ethical Consideration}

In this study the implementation of research ethics followed these steps: assigning an informed consent form, using an anonymity form, keeping the confidentiality, caring for selfdetermination (free to participate or not participate), giving benefits, doing veracity, protecting from discomfort and harm condition, and passing ethical clearance. The ethical issue was obtained from The Research Ethics Commission of the University Muhammadiyah of Semarang. 
respondents $47.1 \%$ were unemployed, more than half of multipara $(64.7 \%)$, more than half of children born were male $(58.8 \%)$, there was still a small percentage who had difficulty giving milk (29.4\%), there were still a small number of mothers who were not sure of the ability of breastmilk to meet nutrition at 6 months first $(23.5 \%)$ and more than half $(52.9 \%)$ abstained from mothers already knew the diet of the puerperal mother but afraid of parents.
Table 1 shows that the majority of respondents in the healthy age range of $76.5 \%$, more than half of respondents had junior high school education $(58.8 \%)$, nearly half of

Table 1 Characteristic of respondents $(\mathrm{N}=34)$

\begin{tabular}{|c|c|c|c|c|}
\hline No & Characteristics & $\mathbf{n}$ & $\%$ & $\mathbf{N}(\%)$ \\
\hline \multirow[t]{3}{*}{1} & Age & & & \\
\hline & a. $15-35$ years & 26 & 76.5 & \\
\hline & b. $>35$ years & 8 & 23.5 & $34(100)$ \\
\hline \multirow[t]{5}{*}{2} & Education & & & \\
\hline & a. Elementary school & 8 & 23,5 & \\
\hline & b. Junior high school & 15 & 44.1 & \\
\hline & c. Senior high school & 9 & 26.5 & $34(100)$ \\
\hline & d. University & 2 & 5.9 & \\
\hline \multirow[t]{4}{*}{3} & Employment & & & \\
\hline & a. Un-employee & 21 & 61.8 & \\
\hline & b. Labor & 11 & 32.4 & $34(100)$ \\
\hline & c. Employee & 2 & 5.9 & \\
\hline \multirow[t]{3}{*}{4} & Parity & & & \\
\hline & a. primipara & 10 & 29.4 & \\
\hline & b. multipara & 24 & 70.6 & $34(100)$ \\
\hline \multirow[t]{3}{*}{5} & Baby’s Sex & & & \\
\hline & a. Female & 14 & 41.2 & \\
\hline & b. Male & 20 & 58.8 & $34(100)$ \\
\hline \multirow[t]{3}{*}{6} & Breastfeeding difficulties & & & \\
\hline & a. Yes & 11 & 32.4 & \\
\hline & b. No & 23 & 67.6 & $34(100)$ \\
\hline \multirow[t]{3}{*}{7} & Confidence in giving breastmilk & & & \\
\hline & a. Confidence & 25 & 73.5 & $34(100)$ \\
\hline & b. Un-confidence & 9 & 26.5 & \\
\hline \multirow[t]{5}{*}{8} & Reasons for food restriction & & & \\
\hline & a. lack of knowledge & 3 & 8.8 & \\
\hline & b. fears of breaking customs & 9 & 26.5 & $34(100)$ \\
\hline & c. afraid of parents & 20 & 58.8 & \\
\hline & d. Others & 2 & 5.9 & \\
\hline
\end{tabular}

\subsection{Productivity of Breast Milk (Based on Children's Weight) in the Treatment Group}

\subsubsection{Baby's weight before and after treatment}

Table 2 shows that there were differences in the minimum and maximum values of the baby's body weight before and after treatment. The minimum amount before treatment was 2700 , and the maximum value was 5300 grams. In the measurement after treatment of giving Moringa extract for one month it was found that the minimum body weight was 3800 grams, and the maximum bodyweight was 5300gram.

Table 2 Baby weight before and after treatment (in the experimental group)

\begin{tabular}{|llccccc|}
\hline No & \multicolumn{1}{c}{ Aspect } & Min & Max & Mean & SD & N (\%) \\
\hline 1 & Baby's weight before the experiment & 2700 & 5300 & 3344.12 & 566.757 & $17(100)$ \\
2 & Baby's weight after experiment & 3800 & 5300 & 4405.88 & 456.167 & $17 \quad(100)$ \\
\hline
\end{tabular}

\subsubsection{Differences in body weight before and after treatment $(N=17)$}

Table 3 shows that there was a difference in average body weight before and after treatment of giving Moringa extract, which is $3344.12 \pm 566.757$ grams before treatment and being $4405.88 \pm 456.167$ grams. The results of the further analysis using paired sample t-test showed that there were significant differences before and after giving Moringa extract with p-value 0,000 and CI (-1308.934) - (-814.595). 
Table 3 The differences in baby weight before and after treatment $(\mathrm{N}=17)$

\begin{tabular}{|lllcl|}
\hline No & \multicolumn{1}{c}{ Aspect } & Mean \pm SD & CI & p-value \\
\hline 1 & Baby weight before treatment & $3344.12 \pm 566.757$ & \multirow{2}{*}{$(-1308.934)-(814.595)$} & 0.000 \\
2 & Baby weight after treatment & $4405.88 \pm 456.167$ & \\
\hline
\end{tabular}

\subsection{Productivity of Breastmilk (Based on Baby's Weight) in the Control Group}

\subsubsection{Weight of babies before and after treatment in the control group}

Table 4 shows that there was a difference in the minimum and maximum values of the baby's body weight before and after treatment in the control group. The minimum amount before treatment was 2600 , and the maximum value was 4000 grams. In the measurement after monitoring for 1 month without Moringa leaves, it was found that the minimum body weight was 3000 grams and the maximum bodyweight was 4900 grams.

Table 4 The differences of baby's weight before and after treatment in the control group

\begin{tabular}{|llccccc|}
\hline No & \multicolumn{1}{c}{ Aspect } & Min & Max & Mean & SD & N (\%) \\
\hline 1 & Baby's weight before treatment & 2600 & 4000 & 3210.29 & 361.336 & $17(100)$ \\
2 & Baby's weight after treatment & 3000 & 4900 & 4135.29 & 487.264 & $17(100)$ \\
\hline
\end{tabular}

\subsubsection{Differences in body weight before and after infants in the control group}

Table 5 shows a significant difference of the means of body weight of the treatment group and the control group. The mean of the treatment group was $3210.29 \pm 361.336$ grams, while the another was $4135.29 \pm 487.264$ grams. The results of further analysis using paired sample t-test showed that there were significant differences in mean before and after treatment with p-value 0.000 and CI (-1098.988) - (751.012).

Table 5 The differences of baby's weight before and after treatment in the control group ( $\mathrm{N}=17)$

\begin{tabular}{|llrcc|}
\hline No & \multicolumn{1}{c}{ Aspect } & Mean \pm SD & CI & p-value \\
\hline 1 & Baby weight before treatment & $3210.29 \pm 361.336$ & \multirow{2}{*}{$(-1098.988)-(751.012)$} & 0.000 \\
2 & Baby weight after treatment & $4135.29 \pm 487.264$ & \\
\hline
\end{tabular}

\subsection{Differences in the Productivity of Breastmilk (Based on the Child's Weight) Between the Treatment Group and the Control Group}

Table 6 The differences of the breastmilk productivity (based on the child's weight) between the treatment and the control group

\begin{tabular}{|rccccccc|}
\hline No & \multicolumn{1}{c}{ Aspect } & Min & Max & Mean & SD & N (\%) & p-value \\
\hline 1 & $\begin{array}{l}\text { the difference of baby weight between } \\
\text { pre-post treatment in the experimental } \\
\text { group } \\
\text { the difference of baby weight between } \\
\text { pre-post treatment in the control group }\end{array}$ & 700 & 900 & 1120.59 & 345.985 & $17(100)$ & 0.049 \\
\hline
\end{tabular}

Table 6 shows that there was a difference in the mean body weight difference in the treatment group had a mean of $1120.59 \pm 345.985$ grams and in the control group had $925.00 \pm 338.397$ grams. The results of further analysis using Mann-Whitney showed that there were mean differences between those given moringa extract and those who only received standard treatment without giving Moringa extract with p-value 0.049 .

\section{DISCUSSION}

Breast milk is an essential source of energy and nutrients in children aged 6to 23 months[3]. Good nutrition during breastfeeding is essential to produce adequate breast milk. This study proves that there were significant effects of moringa oleifera supplementation on breastmilk production among mothers with food restriction. The effect was evaluated by measuring the baby's weight before and after giving supplementation. There were differences between 
body weight before and after treatment, which means that Moringa extract influences on increasing milk production. There is broad micro, and macronutrients in Moringa leaves. The results of the analysis of moringa leaf extract contain vitamin $\mathrm{C}$ and minerals iron $(\mathrm{Fe})$ that are $514.96 \mathrm{mg}$ and $9.72 \mathrm{mg}$ per 100 gram, respectively [4]. Moringa leaves contain complete protein (contains nine essential amino acids), calcium, iron, potassium, magnesium, zinc and vitamins $\mathrm{A}, \mathrm{C}, \mathrm{E}$ and $\mathrm{B}$ which have a significant role in the immune system [6]. It was used in differences cases. A study on mice showed a significant increase the productivity of breast milk in these mice[6]. Research on the other animals revealed that moringa could be a good CP source with all of essential amino acids present in considerable quantities. Based on $\mathrm{CP}$ requirements it could be used for chickens [22\% CP], fattening pigs $[12-14 \%$ $\mathrm{CP}$ ], and lactating cows (16-18\% CP) [7]. could also be used as the preventing and curating babies illness due to the multi-medicinal activities; antimicrobial, antifungal, antihypertensive, anti-hyperlipidemia, anti-hyperglycemic, antipyretic, wound healing, antitumor, anticancer, antiinflammatory and for purification of water[8]. These effects might lead to healthier conditions.

In regards to the breastmilk production, study in humans indicated that moringa increased the level of prolactin and breast milk production on the post-partum mothers [9].A literature review revealed a significant mean increase in prolactin level; milk volume on day seven among mothers who received Moringa by $124 \mathrm{~mL}$ ( $95 \%$ confidence interval, 90-159 mL; heterogeneity $\mathrm{I} 2=0 \% ; \mathrm{p}=0.32)[10]$.

On these cases, mothers restricted for several protein sources such as eggs, meats, beans, fishes and seasoned foods. Due to the kinds of food which were restricted, they need more supplementation in terms of protein, vitamins, minerals and calories as the study suggested, moringa oleifera abundant of the sources of protein, mineral, and so on. It seems to be suitable with the mothers needing, especially breastfeeding mothers.

The effectiveness of moringa oleifera leaf extract to the breastmilk production could be seen from the improvement of the baby weight. American Academy of Paediatrics stated that during the early weeks, the signs of the babies who get enough breast milk are baby nurses about every two hours $(12 \mathrm{x} /$ day), baby has $6-8$ soaking wet diapers per 24 hours, the improvement of the baby's weight (average weight gain is about 4 to 7 ounces per week), and the baby's skin should look healthy [11]. Based on this theory, the researcher took babies weight as an indicator of milk production. It was appropriate because the babies who have been carried out were exclusive breastfeeding babies. It means that babies did not get other nutrition except breastmilk. Therefore, there were no other factors affecting babies weight improvement except the breast milk from the mothers. Ideally, the more breastmilk they got, the higher of the weight gain.

This study suggested that mothers who consumed moringa oleifera had babies that heavier than those who did not consume moringa oleifera. It could be concluded that moringa oleifera extract increased breast milk production based on the baby's weight gain. A pooled analysis of 73 patients showed that moringa oleifera significantly increased the infant's weight during week 4 with a mean difference of $11.9 \%$ (95\% confidence interval, 5.5-18.2\%; heterogeneity I2 $=0 \%$; $\mathrm{p}=0.61$ ) [10]. Another study supporting this conclusion revealed that the noodles substituted by Moringa oleifera leave powder could increase the productivity of breast milk in lactating mothers and then it can be used to alleviate undernourishment of the infants at 0 to 6 months old [12]. Also, because of the content of moringao leifera -including amino acids such as methionine and cysteines also high, while, the carbohydrates, fats and phosphorous content are low- make it one of the finest plant foods to be found and potential to treat malnutrition[13]. This study did not compare the baby's weight gain regarding the parity and mothers age. Further research is needed by considering these factors because age and parity will influence on calcium concentration in milk [14], that might influences also in weight gain.

\section{CONCLUSION}

This study shows that the Moringa extract effectively increases milk production with indicators that there was a difference in weight gain in infants between the control group and the experimental group. It was expected that the results of this study could be one of the references in the implementation of midwifery care for postpartum mothers. Research with more comprehensive variables and more respondents is needed.

\section{ACKNOWLEDGMENT}

Thank you conveyed to the Ministry of Research and Technology who granted research funding.

Besides, The Department of Research, Community Service, and Publication of The University of Muhammadiyah Pekajangan Pekalongan Indonesia for supporting this study.

\section{ETHICAL CONSIDERATION}

Committee of Ethics of Health Research, Faculty of Nursing, University Muhammadiyah of Yogyakarta.

\section{AUTHOR CONTRIBUTIONS}

Conceptualization (M.K, N.C, R.K, S.K); Material research preparation (R.K, S.K); Methodology (M.K, N.C, R.K, S.K); Data collecting (R.K, S.K); Data analysis and visualization (S.K, R.K); Writing - original draft (S.K); Presentation (R.K, S.K).

\section{REFERENCES}

[1] Academy of Nutrition and Dietetics, "Vegetarian Diets During Lactation,” Veg. Nutr., 2010. 
[8] A. Toma and S. Deyno, "Phytochemistry and pharmacological activities of moringa oliefera," no. June, 2014.

[9] Y. Sulistiawati, A. Suwondo, T. S. Hardjanti, A. Soejoenoes, M. C. Anwar, and K. A. Susiloretni, "Effect of Moringa Oleifera on Level of Prolactin and Breast Milk Production in Postpartum Mothers," Belitung Nurs. J., vol. 3, no. 2, pp. 126-133, 2017.

[10] P. F. N. Raguindin, L. F. Dans, and J. F. King, "Moringa oleifera as a galactagogue," Breastfeed. Med., vol. 9, no. 6, pp. 323-324, 2014.

[11] I. Baby and G. Enough, "Breastfeeding — Is Baby Getting Enough?," pp. 1-2.

[12] S. Chandra, P. Dwivedi, and L. P. Shinde, "Significance of Moringa Noodles for Increasing Breast Milk."

[13] R. Dhakar, B. Pooniya, M. Gupta, S. Maurya, N. Bairwa, and Sanwarmal, "Moringa : The herbal gold to combat malnutrition," Chronicles Young Sci., vol. 2, no. 3, p. 119, 2011.

[14] F. Sciences, "Calcium and Magnesium Concentration of Breast Milk in,” vol. 2, no. 1, pp. 329 337, 2012. 